\title{
NUMERICAL STUDY COMPARING THE INCIDENCE INFLUENCE BETWEEN REALISTIC WAVE AND REGULAR WAVE OVER AN OVERTOPPING DEVICE
}

\author{
R. G. Hübnera \\ P. H. Oleinik ${ }^{\mathrm{a}}$, \\ W. C. Marques ${ }^{\mathrm{a}}$, \\ M. N. Gomes ${ }^{\text {, }}$ \\ E. D. dos Santos ${ }^{a}$, \\ B. N. Machadoc, \\ and L. A. Isoldi ${ }^{\mathrm{a}}$ \\ ${ }^{\text {a}}$ Universidade Federal do Rio Grande \\ Av. Itália, km 8, \\ Carreiros, Rio Grande, RS \\ rikhubner@gmail.com \\ phe.h.o1@gmail.com \\ wilianmarques47@gmail.com \\ elizaldosantos@furg.br \\ liercioisoldi@furg.br \\ ${ }^{\mathrm{b}}$ Instituto Federal do Paraná
}

Av. Victor Ferreira do Amaral, 306, $3^{\circ}$ andar.

Tarumã, Curitiba, PR

mateus.gomes@ifpr.edu.br

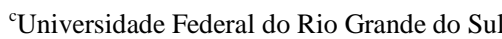

Av. Paulo Gama, 110

Farroupilha, Porto Alegre -RS.

bianca.machado@ufrgs.br

\section{ABSTRACT}

This work presents a numerical study to evaluate the difference between the fluid dynamic behavior of an overtopping device subjected to the incidence of a realistic wave when compared to a regular one; being this regular wave representative of the considered realistic sea state. To do so, the FLUENT software was employed, which is a Computational Fluid Dynamics package based on the Finite Volume Method. The regular wave was generated through a User Defined Function (UDF) that imposes its velocities components as boundary conditions of prescribed velocity. On the other hand, for the realistic wave it was used a methodology to impose the realistic components velocities from transient discrete values, named Table Data (TD) in FLUENT software. For both cases the Volume of Fluid (VOF) multiphase model was applied in the treatment of the water-air interaction. The results showed that the amount of water accumulated in the reservoir for the realistic sea state was 2.46 higher than for the regular wave. This is a relevant finding, since several researches about Overtopping device efficiency were promoted considering only the incidence of regular wave.

Keywords: overtopping; wave energy; realistic sea state

Received: February 28, 2019

Revised: March 21, 2019

Accepted: April 22, 2019

\section{NOMENCLATURE}

A wave amplitude, m;

$\mathrm{A}_{1} \quad$ ramp area, $\mathrm{m}^{2}$;

CFD computational fluid dynamics;

g gravity, $\mathrm{m} / \mathrm{s}^{2}$;

h channel depth, m;

$\mathrm{H}$ wave height, $\mathrm{m}$;

$\mathrm{H}_{1} \quad$ ramp height, m;

$\mathrm{k}$ number of waves;

$\mathrm{L}_{1} \quad$ ramp length, $\mathrm{m}$;

$\mathrm{L}_{\mathrm{R}} \quad$ reservoir length, $\mathrm{m}$;

MFV method of finites volumes;

$\mathrm{S}$ dispositive depth, $\mathrm{m}$;

$\mathrm{t}$ time, $\mathrm{s}$

T wave period, s;

TD table data;

$\overline{\bar{\tau}} \quad$ viscous stress tensor, $\mathrm{N} / \mathrm{m}^{2}$;

$\mathrm{u}$ horizontal velocity, $\mathrm{m} / \mathrm{s}$;

UDF user defined function;
$\vec{v} \quad$ velocity vector, $\mathrm{m} / \mathrm{s}$;
$\mathrm{v} \quad$ vertical velocity, $\mathrm{m} / \mathrm{s}$;
VOF volume of fluid;
WEC wave energy converter
$\mathrm{x}, \mathrm{y}, \mathrm{z}$ cartesian coordinates, $\mathrm{m}$

\section{Greek symbols}

$\alpha \quad$ volume fraction;

$\lambda \quad$ wave length, $\mathrm{m}$;

$\sigma \quad$ wave frequency, $1 / \mathrm{s}$;

$\eta \quad$ free surface elevation, $\mathrm{m}$;

$\mu \quad$ viscosity, $\mathrm{kg} / \mathrm{ms}$;

$\rho$ density, $\mathrm{kg} / \mathrm{m}^{3}$.

\section{INTRODUCTION}

Currently there is a growing demand for energy to supply the humanity. This happens mainly due to the population growth in underdeveloped countries and the consumerism in developed countries (Fontana 
et al., 2015). According to the Living Planet Report (2016), since 1971 the mankind's demand was become greater than the planet ability to regenerate. Therefore, a change in a pattern of consumption, technologies and infrastructure is necessary in order to change this tendency.

In the context of technologies and infrastructure the renewable energy sources can be applied. Among them, one which still unexplored is the ocean wave energy. According to Espindola and Araujo (2017) the average energy potential of the oceanic waves in the Brazilian coast is estimated at $12.01 \mathrm{~kW} / \mathrm{m}$ and an Overtopping device in the southern region of the country can reach productions of up to $10.42 \mathrm{GWh}$. In addition, the ocean of the Brazilian coast presents low temporal variation, which is good to the project and installation of the Wave Energy Converters (WEC).

The Overtopping device consists basically of a ramp, a reservoir and a turbine for converting the sea wave energy into electrical energy. The waves propagate, climb the ramp and fill the reservoir creating a water column height; this water is directed to the turbine that generates electricity (Fleming, 2012). The Fig. 1 illustrates the operating principle of this device.

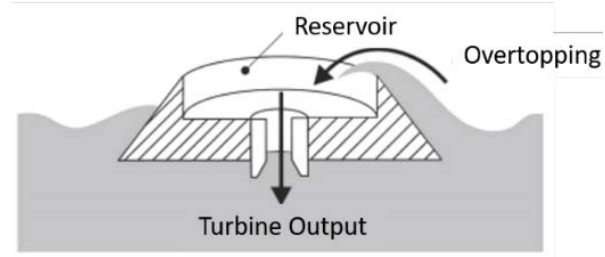

Figure 1. Diagram of the operating principle of an Overtopping device.

There are many articles in the literature relating about the WECs. Most of then use the computational approach. Some important contributions about the Overtopping devices and methods for numerical wave generation, which are the focus of the present study, will be presents bellow.

Margheretini et al. (2012) developed a numerical study of geometric optimization of a multistage overtopping device in order to evaluate the viability of implementing this converter at the Hanstholm port in Denmark. The WOPSim software was used and the incidence of irregular waves was considered on the device using the JONSWAP spectrum.

In Martins et al. (2016) a numerical study evaluating the difference in the results of an Overtopping device under the incidence of a monochromatic wave or wave spectrum was presented. For the numerical solution, a CFD code based on MVF was used. The multi-phase VOF model was used to treat the water-air interaction.

Suzuki et al. (2017) evaluated the applicability of the SWASH model for transforming incident waves into an Overtopping device. The governing equations of a SWASH model are the non-linear shallow water equations with additional nonhydrostatic effects.

In Machado et al. (2017) a real-scale and a laboratory-scale wave tank were analyzed to evaluate a new method of imposing the velocity boundary condition for regular wave generation using transient discrete values. To realize this study, FLUENT software was used, which is a CFD package based on MVF.

Martins et al. (2017) evaluated the geometry of an Overtopping WEC using the Constructal Design. The equations of mass conservation, momentum and transport of the volumetric fraction of water were solved in FLUENT. The multi-phase VOF model was used to treat the water-air interaction.

Han et al. (2018) a multi-stage overtopping WEC device and the effect of change some dimensions. For this work, they used the FLUENT software and developed a numerical wave tank based on the VOF model, considering the incidence of regular waves on the device.

In this context, the present work deals with the incidence of a realistic sea state over an Overtopping converter using the methodology proposed by Machado et al. (2017). The results will be compared to those obtained by the incidence of a regular wave representative of this realistic sea state, i.e., a regular wave with height and period defined, respectively, as the significant height and peak period of the realistic sea state. The transient discrete values used to generate de realistic sea state were obtained using the methodology proposed by Oleinik (2017) for a wave located on the coast of the Ingleses beach, on the Island of Florianópolis - SC. The start of the wave tank has coordinates $27^{\circ} 25^{\prime} 59.1^{\prime \prime} \mathrm{S}$ and $48^{\circ} 23^{\prime} 19.6^{\prime \prime}$ $\mathrm{W}$ while its end touches the coast at $27^{\circ} 26^{\prime} 6,16^{\prime \prime} \mathrm{S}$ and $48^{\circ} 23$ '28.5” $\mathrm{W}$.

The main objective of this study is to evaluate the differences in the fluid dynamics behavior of the Overtopping device when subjected to these two situations: realistic waves of a sea state and regular waves representative of this sea state.

To do so, the study will be considered the optimum geometry proposed by Martins (2016) for monochromatic waves with some adaptations. The ramp of the device have the ratio $\mathrm{H}_{1} / \mathrm{L}_{1}=0.33$, the distance from the bottom of the device to the bottom of the numerical wave tank is $3.5 \mathrm{~m}$ and the length of the reservoir is $L_{R}=20 \mathrm{~m}$.

\section{PROBLEM DESCRIPTION}

As aforementioned, the analyzed problem consists of an Overtopping WEC device into a numerical wave tank, as shown in Fig. 2. The wave is generated by imposing the prescribed velocity on part of the left lateral surface (green line) of the numerical wave tank. The both cases analyzed (realistic and 


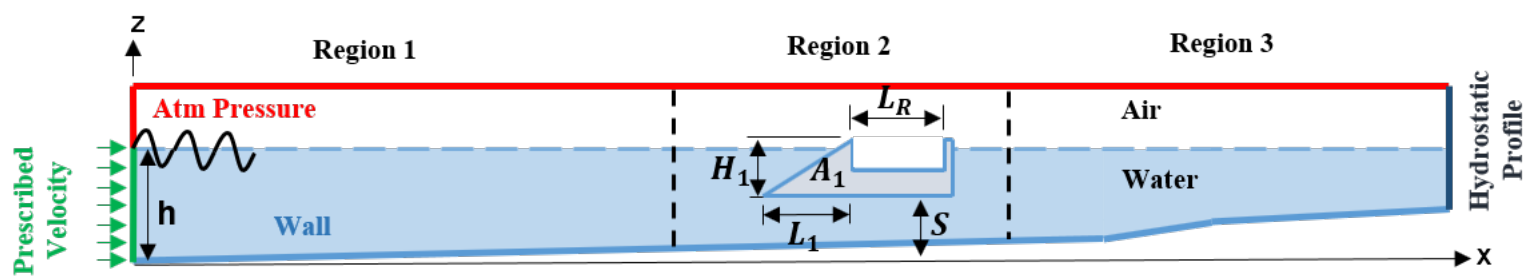

Figure 2. Computational domain ilustration.

regular waves), in this work, have different methodologies for the application of the prescribed velocity. It is important to note that Machado et al. (2017) compared the generation of a regular wave with the two different models: employing the velocity wave components by means its equations as User Defined Function (UDF) in FLUENT or imposing transient discrete data for the velocity wave components by the Table Data (TD) in FLUENT. It is important to highlight that there is no significant difference between the generated regular waves with these methodologies.

As can be seen in Fig. 2, the bottom is inclined and this slope was defined by the bathymetry of the region in which the discrete realistic values of the velocities $\mathrm{u}$ and $\mathrm{w}$ were obtained. Moreover, the computational domain was divided into three regions that will be treated and discretized in different ways. Region 1 is the wave generation and propagation region; Region 2 is the region of the device where the interaction among water, air and structure occurs; and the region 3 is the place where the numerical beach is added to dampen the wave and prevent the phenomenon of wave reflection.

According to Machado et al. (2017), the methodology using transient discrete values, also called in FLUENT of Table Data, presents a particularity in the computational domain: the surface where the prescribed velocity boundary condition is imposed, through $\mathrm{u}$ and $\mathrm{w}$ components, must be divided into sub-regions, as shown in Fig. 3.
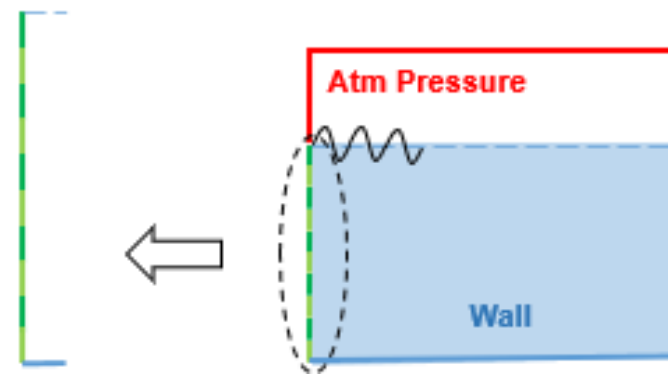

Figure 3. Detail of sub-regions needed to impose the wave velocity components as boundary conditions (Machado et al., 2017).

The GAMBIT software was used for construction and discretization of the computational domain. The numerical simulations were performed using the FLUENT software, which is based on MFV. The multi-phase VOF model was used to treat the water-air interaction.

\section{MATEMATHICAL MODEL}

As before mentioned, two different methods were used for wave generation. The first one, which uses a UDF in FLUENT, allows generation of regular waves. The second one, which in FLUENT employs the Table Data tool, allows both generation of regular and realistic wave, according to Machado et al. (2017).

The first method is based on the imposition of equations representing the components $u$ and $w$ of the velocity of a regular wave. In FLUENT this is possible due to the UDF tool. This methodology is widely used, as in the Machado et al. (2017), Martins et al. (2017), and Han et al. (2018).

The regular wave used in the present work represents the realistic sea state (second method) obtained by Oleinik (2017), having the following characteristics: peak period $\mathrm{T}=11.1 \mathrm{~s}$, significant height $\mathrm{H}_{\mathrm{S}}=0.355 \mathrm{~m}$, and length $\lambda=96.9 \mathrm{~m}$. This regular wave will be represented by the Second Order Stokes theory, because according to Chakrabarti (1987) this is the theory that best applies to these characteristics in a propagation depth of $8.5 \mathrm{~m}$. Thus, according to the Dean and Dalrymple (1991) the horizontal and vertical velocity components of the wave were given, respectively, by: boundary condition of prescribed velocity is given by the following equations:

$$
\begin{array}{r}
u=A g k \frac{\cosh (k z+k h)}{\sigma \cos (k h)} \cos 2(k h-\sigma t)+ \\
+A^{2} \sigma k \frac{\cosh 2 k(h+z)}{\operatorname{sen}^{4}(k h)} \cos 2(k x-\sigma t) \\
w=A g k \frac{\sinh (k z+k h)}{\sigma \sin (k h)} \sin (k x-\sigma t)+ \\
+A^{2} \sigma k \frac{\sinh 2 k(h+z)}{\cos ^{4}(k h)} \sin 2(k x-\sigma t)
\end{array}
$$

where $\mathrm{u}$ and $\mathrm{w}$ are the horizontal and vertical components of velocity $(\mathrm{m} / \mathrm{s}), A$ is the wave amplitude (m), $\mathrm{g}$ is the gravitational acceleration 
$\left(\mathrm{m} / \mathrm{s}^{2}\right), \mathrm{k}$ is the wave number given by $\mathrm{k}=2 \pi / \lambda, \mathrm{h}$ is the depth (m), $\lambda$ is the wave length (m), $T$ is the wave period (s), $\sigma$ is the frequency given by $\sigma=2 \pi / \mathrm{T}(\mathrm{Hz})$, $\mathrm{x}$ is the streamwise coordinate $(\mathrm{m}), \mathrm{t}$ is the time (s) and $\mathrm{z}$ is the normal coordinate $(\mathrm{m})$.

Equations (1) and (2) are imposed as boundary conditions of prescribed velocity by means the UDF tool in FLUENT software.

Furthermore, according to Dean and Dalrymple (1991) the equation representing the free surface elevation of the regular wave is defined as:

$$
\begin{aligned}
\eta & =\frac{H}{2} \cos (k x-\sigma t)+ \\
& +H^{2} \frac{k \cosh (k h)}{16 \sinh ^{3}(k h)}(2+\cosh (2 k h)) \cos 2(k x-\sigma t)
\end{aligned}
$$

where $\eta$ is the free surface elevation (m) and $H$ is the wave height $(\mathrm{m})$.

Equation (3) can be used to verify the computational model proposed to generate regular waves.

The second method allows generating irregular waves reproducing a realistic sea state by the use of the methodology proposed by Machado et al. (2017). For this, the segment for the imposition of the velocity boundary condition must be divided into many others segments (see Fig. 3) in which the transient discrete velocities values obtained through the methodology propose by Oleinik (2017) are imposed.

By the use of Table Data methodology, proposed by Machado et al. (2017), the data are inserted into FLUENT through tables, called Boundary Profiles, allowing discrete transient data, in this case with realistic wave velocity components $\mathrm{u}$ and $w$, imposed as boundary condition of prescribed velocity.

In this work, the segment for the imposition of the velocity boundary condition was sub-divided in 14 sub-regions, according to the values generated by Oleinik (2017). In each one of this 14 sub-regions, the components $\mathrm{u}$ and $\mathrm{w}$ are defined with a time step of $0.05 \mathrm{~s}$.

\section{COMPUTATIONAL MODEL}

To realize this study, it is necessary to treat the interaction between water and air. To do so, the multi-phase methodology VOF will be utilized. This method considers that the volume of one phase cannot be occupied by another phase. To represent each phase present in each control volume, the volume fraction $\alpha$ is calculated. As the present work considers only the interaction between two phases (water and air), this fraction varies between 0 and 1 , where 0 indicates that the measured phase is not present in that volume and 1 indicates that only the measured phase is present in that volume. Therefore, $\alpha_{\text {air }}=1-\alpha_{\text {water }}$ (Hirt and Nichols, 1981).

Furthermore, when the VOF is applied are solved the equations of momentum and continuity for each component of the flow in each control volume. Besides, the volume fraction $\alpha$ is calculated for each control volume in the entire computational domain trough the transport equation for one of the phases. Then, the following equations are solved (Hirt and Nichols, 1981):

$$
\frac{\partial(\rho \vec{v})}{\partial t}+\nabla \cdot(\rho \vec{v} \vec{v})=-\nabla \rho+\nabla \cdot(\mu \overline{\bar{\tau}})+\rho \vec{g}
$$

$$
\begin{gathered}
\frac{\partial(\rho)}{\partial t}+\nabla \cdot(\rho \vec{v})=0 \\
\frac{\partial(\rho \alpha)}{\partial t}+\nabla \cdot(\rho \alpha \vec{v})=0
\end{gathered}
$$

where $\rho$ is the fluid density $\left(\mathrm{kg} / \mathrm{m}^{3}\right), \vec{v}$ is the velocity vector of flow $(\mathrm{m} / \mathrm{s}), \mu$ is the viscosity $(\mathrm{kg} / \mathrm{ms}), \overline{\bar{\tau}}$ is the viscous stress tensor $\left(\mathrm{N} / \mathrm{m}^{2}\right)$.

It is still important to note that the Eqs. (4) and (5) are solved for the mixture. Thus, it is necessary to obtain the values of density and viscosity, respectively (Srinivasan et al., 2011):

$$
\begin{aligned}
& \rho=\alpha_{\text {water }} \rho_{\text {water }}+\alpha_{\text {air }} \rho_{\text {air }} \\
& \mu=\alpha_{\text {water }} \mu_{\text {water }}+\alpha_{\text {air }} \mu_{\text {air }}
\end{aligned}
$$

Therefore, the equations used in this work are numerically solved using the FLUENT software, which is a commercial code based on MFV (Fluent, 2016). To the treatment of the advective terms in the momentum equation it was adopted the first order upwind scheme, while pressure spatial discretization was performed using the PRESTO method. The COMPRESSIVE method is applied to the volume fraction. Regarding the pressure-velocity coupling the PISO method was adopted. Furthermore, the subrelations of mass and momentum conservation equations of 0.30 and 0.70 were employed, respectively.

\section{RESULTS AND DISCUSSIONS}

The mesh convergence test and the computational model verification were performed for the regular wave. The same mesh was adopted in the numerical simulation with realistic data, as in Machado et al. (2017).

As earlier mentioned, the spatial discretization was differently treated for each region shown in Fig. 2 . In the wave generation and propagation region (Region 1 in Fig. 2) and in the numerical beach region (Region 3 in Fig. 2) it was used the same discretization formed by square computational cells, while the region of the Overtopping device (Region 2 in Fig. 2) it was discretized with triangular cells 
forming an irregular mesh. This discretization with irregular triangle mesh was used because it is the one that best adapts to complex geometry, as indicated by Iahnke (2010) and Machado (2012).

For the numerical model verification, the free surface elevation obtained through the computational simulation was compared with that generated by Eq. (3). For this, three different spatial discretization were tested. For each one the Mean Absolute Error (MAE) was defined comparing the obtained numerical result and the analytical result from Second Order Stokes theory, given by Eq. (3). Table 1 presents the computational cell size, the total elements of the mesh and the MAE value for each analyzed mesh.

Table 1 . Mesh quality study

\begin{tabular}{|c|c|c|}
\hline Cell Size (m) & Mesh Elements & MAE (\%) \\
\hline 0.7 & 7,308 & 13.65 \\
\hline 0.5 & 15,504 & 5.31 \\
\hline 0.3 & 41,440 & 2.02 \\
\hline
\end{tabular}

With the results shown in Tab. 1, the spatial discretization by the mesh with $0.30 \mathrm{~m}$ regular squares for Region 1 and 3 and $0.30 \mathrm{~m}$ irregular triangles for Region 2 was chose to use. The obtained numerical result with this mesh is compared to the analytical one in Fig. 4.

In order to compare the fluid dynamic behavior of the Overtopping WEC over the incidence of irregular waves representing a realistic sea state and regular waves representative of this realistic sea state, both situations are presented in Fig. 5 for the instantaneous mass flow rate of water at the reservoir and in Fig. 6 for the free surface elevation. It is important to mention that the mass flow rate of water was obtained considering the wave tank with a unit width $(1 \mathrm{~m})$.

As can be observed in Fig. 5, near to $900 \mathrm{~s}$ of simulation the reservoir began to overflow for the case of realistic sea state (blue line), in this way all carried out evaluations in the present study consider only the data collected until the time of $850 \mathrm{~s}$. It can be observed that for regular wave there is a more stable behavior of the mass flow rate, always with smaller values and at approximately constant time intervals. However, for the realistic sea state, the peak flow values were larger and with a lot of variation.

Furthermore, it is possible to evaluate the two main flow peaks for the realistic sea state. The first one occurred at $326.72 \mathrm{~s}$ and the second one at $701.23 \mathrm{~s}$ with values of $1,254.17 \mathrm{~kg} / \mathrm{s}$ and $1,383.62$ $\mathrm{kg} / \mathrm{s}$, respectively (see Fig. 5). Considering the celerity of the wave $(\lambda / \mathrm{T}=8.72 \mathrm{~m} / \mathrm{s})$ and the distance between the elevation monitor and the input of the reservoir $(145 \mathrm{~m})$ it is possible to conclude that the wave heights that promote these peak flows are detected in the elevation monitors at times $310.90 \mathrm{~s}$ and 684.60 s. These instants are shown in Fig. 6 and the corresponding heights are 0.74 and $1.17 \mathrm{~m}$, respectively.

It is still important to evaluate that for the regular wave the first peak occurred at $\mathrm{t}=31.60 \mathrm{~s}$, with a value of $216.83 \mathrm{~kg} / \mathrm{s}$. For the realistic sea state, the first peak occurred at $\mathrm{t}=32.72 \mathrm{~s}$ with a value of $63.82 \mathrm{~kg} / \mathrm{s}$. Figure 7 shows the hydrodynamic behavior of the analyzed problem for the mentioned instants. It should be noted that the red color indicates the presence of water and the blue color indicates the presents of air.

As can be seen in Fig. 7, in both cases, the overtopping started almost at the same instant of time, but the initial mass flow rate was higher for the regular wave than for the irregular realistic wave.

The maximum mass flow for the regular wave was obtained at time $\mathrm{t}=53.50 \mathrm{~s}$ with the value of $293.46 \mathrm{~kg} / \mathrm{s}$, while for the realistic wave the maximum value obtained for the mass flow was $1,383.62 \mathrm{~kg} / \mathrm{s}$ and occurred at time $\mathrm{t}=701.23 \mathrm{~s}$ (see Fig. 5). The Figure 8 shows the hydrodynamic behavior of the analyzed problem for both instants of time.

It is possible to observe in Fig. 8 that the maximum values were detected at different time in each case, in addition the maximum mass flow rate was 4.71 times higher for the realistic wave than for the regular wave.

Furthermore, it is important to note that the total amount of water in the reservoir in the instant of $850 \mathrm{~s}$ was $25,540.37 \mathrm{~kg}$ for the representative regular wave and 62,953.76 $\mathrm{kg}$ for the realistic sea state, indicating that the amount of water that entered in the reservoir was 2.46 times higher for the realistic sea state than for the representative regular wave.

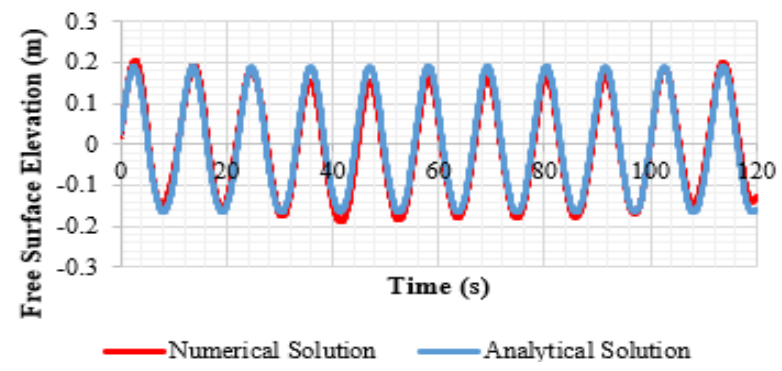

Figure 3. Comparison between the numerical solution and the analytical solution. 


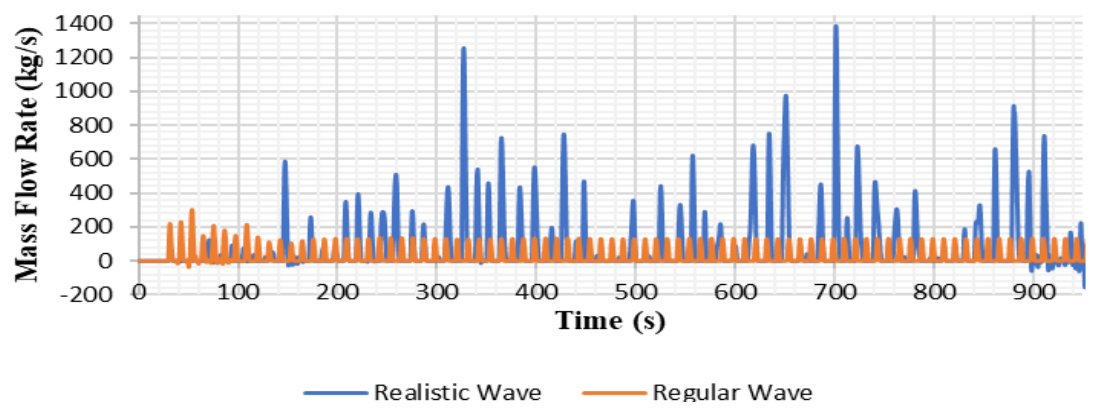

Figure 4. Comparison between the mass flow rate for each one of the methodologies applied.

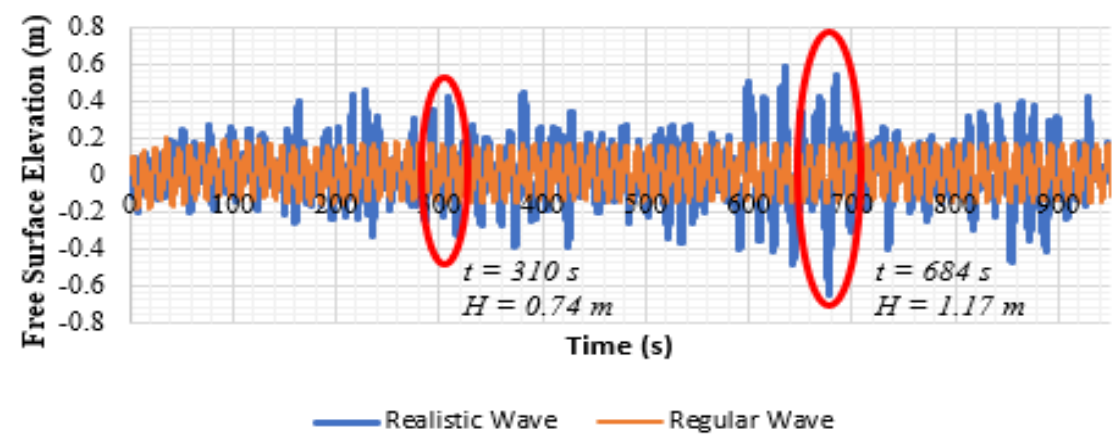

Figure 5. Comparison between the free surface elevation for each one of the methodologies applied.

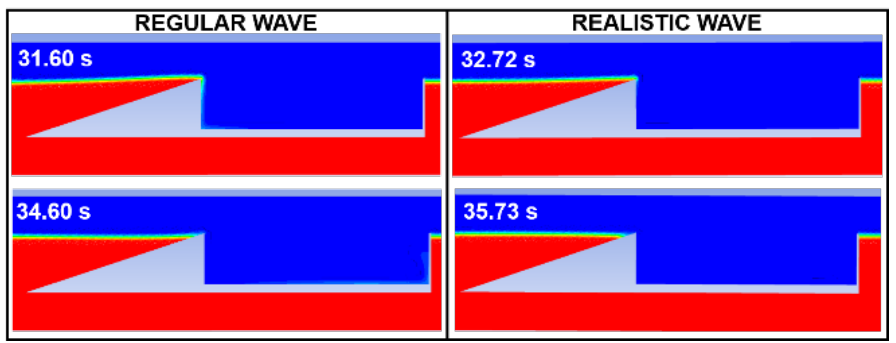

Figure 7. Hydrodynamics behavior of the device in the first peak of mass flow to each applied methodology.

\begin{tabular}{|l|l|}
\hline \multicolumn{2}{|c|}{ REGULAR WAVE } \\
\hline $53.50 \mathrm{~s}$ \\
\hline
\end{tabular}

Figure 8. Hydrodynamics behavior of the device in the maximum peak of mass flow for each applied methodology.

\section{CONCLUSION}

The present work presented a comparison of the behavior of an Overtopping WEC device over the incidence of an irregular wave (reproducing a realistic sea state) and a regular wave (representative of this realistic sea state). In FLUENT software, the irregular wave was generated through the prescribed velocity boundary condition imposed by the Table
Data methodology and the regular wave had the prescribed velocity boundary condition imposed by the UDF methodology.

Concerning the instantaneous mass flow, for the representative regular wave the peaks are smaller and more stable (with low variation) than for the realistic sea state. In addition, the maximum mass flow rate peak for the realistic wave was about 4.71 times greater than for the regular wave. 
In relation to the behavior in time, the two methodologies presented similar results regarding the instant of time when the first overtopping occurred. However, the instant when the maximum mass flow occurred had a difference about $648 \mathrm{~s}$ from the irregular wave to regular wave.

Considering the amount of water that entered into the reservoir, it can be observed that for the period of $850 \mathrm{~s}$ entered 2.46 times more water for the realistic sea state than for the representative regular wave.

It is important to note that this is the first study comparing the effects of the incidence of a realistic sea state over an Overtopping device. The significant difference found between the hydrodynamic behaviors of two situations indicates the importance of performing others studies about this theme.

\section{ACKNOWLEDGMENT}

R. G. Hübner thanks the CNPq for the master's scholarship. This study was financed in part by the Coordenação de Aperfeiçoamento de Pessoal de Nível Superior - Brasil (CAPES) - Finance Code 001 (P. H. Oleinik). The authors W. C. Marques, E. D. dos Santos, L. A. Isoldi thank the CNPq for the Research Productivity grants. The author L. A. Isoldi thank the FAPERGS for the appeal approved in Bid 02/2017 - PqG, process 17/2551-0001-111-2.

\section{REFERENCES}

Chakrabarti, S. K., 2005, Handbook of Offshore Engineering, Vol. 1, Elsevier.

Dean, R. G., and Dalrymple, R. A., 1991, Water Wave Mechanics for Engineers and Scientists, Vol. 2, World Scientific, Singapura.

Espindola, R. L., and Araújo, A. M., 2017, Wave Energy Resource of Brazil: an Analysis from 35 Years of ERA-Interim Reanalysis Data, PLoS ONE.

Fleming, F. P., 2012, Avaliação do Potencial de Energias Oceânicas no Brasil, Master Thesis, Universidade Federal do Rio de Janeiro, Rio de Janeiro. (in Portuguese)

Fontana, R. L. M., Costa, S. S., Silva, J. A. B., and Rodrigues, A. J., 2015, Teorias Demográficas e o Crescimento Populacional no Mundo, Cadernos de Graduação, Ciências Humanas e Sociais Unit, Aracajú, Vol. 2, No. 3, pp 113-124. (in Portuguese)

Han, Z., Liu, Z., and Shi, H., 2018, Numerical Study on Overtopping Performance of a Multi-Level Breakwater for Wave Energy Conversion, Ocean Engeneering, Vol. 150, pp. 94-101.

Hirt, C., and Nichols, B., 1981, Volume of Fluid (VOF) Method for the Dynamics of Free Boundaries, Journal of Computational Physics, Vol. 39, No. 1, pp. 201-225.

Iahnke, L., P., 2010, Energia das Ondas: estado da Arte e Desenvolvimento de um Modelo de
Simulação Numérica para o Princípio de Galgamento, Master Thesis, Universidade Federal do Rio Grande, Rio Grande, RS. (in Portuguese)

Machado, B. N., Kisner, E. V., Paiva, M. S., Gomes, M. N., Rocha, L. A. O., Marques, W. C., Santos, E. D., and Isoldi, L. A., 2017, Numerical Generation of Regular Waves Using Discrete Analytical Data as Boundary Condition of Prescribed Velocity, in: XXXVIII Iberian Latin-American Congress on Computational Methods in Engineering, ABMEC, Florianópolis, SC.

Machado, B. N., 2012, Modelagem Computacional e Otimização Geométrica de um Dispositivo de Galgamento para a Conversão da Energia das Ondas do Mar em Energia Elétrica, Master Thesis, Universidade Federal do Rio Grande, Rio Grande, RS. (in Portuguese)

Margheritini, L., Stratigaki, V., and Troch, P., 2012, Geometry Optimization of an Overtopping Wave Energy Device Implemented into the New Breakwater of the Hanstholm Port Expansion, in: Twenty-Second International Offshore and Polar Engineering Conference, At Rhodos, Greece.

Martins, J. C., Goulart, M. M., Barbosa, D. V., Gomes, M. N., Souza, J. A., Rocha, L. A., and Santos, E. D., 2016, Estudo Numérico de um Espectro de Ondas Comparado a uma Onda Monocromática sobre um Dispositivo de Galgamento Onshore Empregando Design Construtal, in: Seminário e Workshop em Engenharia Oceânica VII Semengo, Rio Grande, RS, pp. 202-211. (in Portuguese)

Martins, J. C., Goulart, M. M., Gomes, M. N., Souza, J. A., Rocha, L. A. O., Isoldi, L. A., and Santos, E. D., 2018, Geometric Evaluation of the Main Operational Principle of an Overtopping Wave Energy Converter by Means of Constructal Design, Renewable Energy, Vol. 118, pp. 727-741.

Oleinik, P. H., 2017, Desenvolvimento e Aplicação de um Modelo Acoplável de Conversão de Energia de Ondas, Trabalho de Conclusão de Curso, Universidade Federal do Rio Grande, Rio Grande, RS. (in Portuguese)

Srinivasan, V. Salazar, A. J., and Saito, K., 2011, Modeling the Disintegration of Modulated Liquid Jets Using Volume-of-Fluid (VOF) Methodology, Applied Mathematical Modeling, Vol. 35, No. 8, pp. 3710-3730.

Suzuki, T., Altomare, C., Veale, W., Verwast, T., Trouwn, K., Troch, P., and Zijlema, M., 2017, Efficient and Robust Wave Overtopping Estimation for Impermeable Coastal Structures in Shallow Foreshores Using SWASH, Coastal Engeneering, Vol. 122, pp. 108-123.

WWF, 2016, Planeta Vivo Relatório 2016 Risco e Resiliência em uma Nova Era, WWFInternational, Gland, Suiça. (in Portuguese) 